\title{
Depression and Poverty II. Strategies for Intervention
}

Donald C. Ohuoha, M.D., M.P.H.

St. Elizabeth's Hospital, Washington DC

Follow this and additional works at: https://jdc.jefferson.edu/jeffjpsychiatry

Part of the Psychiatry Commons

Let us know how access to this document benefits you

\section{Recommended Citation}

Ohuoha, M.D., M.P.H., Donald C. (1991) "Depression and Poverty II. Strategies for Intervention," Jefferson Journal of Psychiatry. Vol. 9 : Iss. 1 , Article 5.

DOI: https://doi.org/10.29046/JJP.009.1.003

Available at: https://jdc.jefferson.edu/jeffjpsychiatry/vol9/iss1/5

This Article is brought to you for free and open access by the Jefferson Digital Commons. The Jefferson Digital Commons is a service of Thomas Jefferson University's Center for Teaching and Learning (CTL). The Commons is a showcase for Jefferson books and journals, peer-reviewed scholarly publications, unique historical collections from the University archives, and teaching tools. The Jefferson Digital Commons allows researchers and interested readers anywhere in the world to learn about and keep up to date with Jefferson scholarship. This article has been accepted for inclusion in Jefferson Journal of Psychiatry by an authorized administrator of the Jefferson Digital Commons. For more information, please contact: JeffersonDigitalCommons@jefferson.edu. 


\title{
Depression and Poverty II. Strategies for Intervention
}

\author{
Donald C. Ohuoha, M.D., M.P.H.
}

\begin{abstract}
In Part I of this paper, I reviewed the recent findings in psychosocial causes of depression among the poor, and questions raised by them. In this paper, I will suggest certain strategies for intervention for treatment of this population.
\end{abstract}

\section{INTRODUCTION}

It is clear that the delivery of mental health services to the poor has not only been a failure, in some places it has been non-existent. Part of the problem lies in the fact that clinicians often have no perception of needs, goals of this population or the ability to evaluate treatment outcomes. These are especially important in designing and implementing community services that are sensitive to local needs as defined by the community. For example, if depressed patients in the community are mainly concerned with loss of energy, multiple aches and pains. It is likely to be unproductive for the clinician to ignore these complaints and focus on anhedonia, more typical depressive complaints amongst western patients, even if these factors can be elicited as signs of depression in a sensitive clinical interview. It is important that accurate diagnosis be made.

Understanding the relationship between the core features and local presentations of depression and understanding the relationship between culture and factors related to vulnerability will make it easier for the clinician to determine pertinent symptoms more effectively. It is essential to understand that cultural factors may necessitate that patients to choose among various kinds of healers, doctors, and others who offer relief from distress. In planning mental health service in especially medically pluralistic settings, understanding the local culture will help explain certain problems like delay in seeking mental health services, poor compliances with recommendations for treatment and preferences for less effective alternatives. It is also important to understand differences in the perception of needs, goals and assessment of treatment outcome as lay persons, clinicians and health planners understand them. It is important to understand that transformation of loss, grief and poverty into depression varies across cultures and how culturally accepted rituals or other coping mechanisms related to that transformation, vary across cultures.

Clinicians must be aware of biological differences amongst patients across cultures and of the local interpretation and acceptance of symptoms and difficult 
effects of medication, which may influence the choice of drugs and dosages for different populations. Psychological differences may indicate different paradigms for the relationship between therapist and patient. Clinicians must understand culture specific cognitive therapies that are responsive to moral values which will be more effective than transplanted therapies that ignore social norms, values and beliefs. Treatment which involves psychotherapy with poor people, as with anyone, should bolster self-esteem, extinguish self-defeating behavior and attitudes and foster a more adequate perception of both the patient's capacities and limitations and the limitations of the environment. Clinicians cannot dismiss real problems of poverty or insulate themselves from understanding the precipitating factors. Clinicians must be ready to understand and deal with behavioral and intrapsychic problems. They should keep in mind the pervasive impact of poverty so as to try to alleviate this impact as much as possible (1).

Clinicians must clarify for themselves whether they perceive poverty and lower class mainly as a result of personal defects or as institutionalized oppression so as to effectively deal with depression caused by poverty (2). When teaching poor patients, clinicians should be careful to avoid reinforcement of negative self image and the generalized feeling of demoralization engendered by poverty. One pervasive assumption is that the poor cannot benefit from the more prestigious therapeutic interventions such as psychoanalysis and psychodynamic therapies and that they require more directive and even authoritarian therapeutic approaches. This is only a reflection of the negative attitudes and prejudices shared by clinicians and society as a whole towards the poor and working class $(3,4)$. Most clinicians tend to prefer young attractive, verbal, intelligent and vocationally successful patients. (The YAVIS phenomena described by Schonfield, (5)). The poor generally do have most of these traits. Halleck (6) writes that psychiatric neutrality is "a myth" and Bart (7) notes that "where poverty has been discovered by psychotherapists, the basic image of man has changed from passive clients to active participants and planners in matters affecting his destiny."

"To blame the victim while pretending to help is unjustifiable and can only reproduce the experience of rejection, devaluation and demoralization that brings patients into treatment in the first place. Charity cannot substitute for justice, and therapists who cannot or will not see poor patients as victims of injustice would do well to refer themselves elsewhere" (8).

\section{Therapeutic Tactics}

Physicians and mental health workers who choose to serve the poor need to not only be aware of the psychosocial and moral cultural and racial attitudes towards the population, but also need to creatively develop tactics that enhance the effectiveness of their therapeutic interventions. It may be useful to think of treatment in this population as intervention-based, educative-based, and then traditional modalitiesbased. It must incorporate mutual collaboration characterized by warmth, empathy, respect and egalitarian attitudes (8). 


\section{Intervention Stance}

Often poor depressed patients come into the mental health delivery system during times of crisis. Clinicians must address this crisis not only with appropriate crisis intervention skills, but must also seek out all the available social welfare subsidies that might remedy each appropriate situation prior to beginning more traditional treatment modalities. Clinicians should be aware of eligibility requirements in public health programs, nutritional supplements, housing and financial assistance programs or refer those patients to appropriate agencies. One may need to stabilize these patients' immediate stressors before traditional treatment interventions can work. It is important to understand help-seeking patterns and ways in which these patterns are responsive to both cosmopolitan and culture specific features of depressive illness.

\section{Educative Stance}

Poor patients must be educated and made partners in the process of treatment interventions, particularly when the mode of formal help known to these patients are mostly religious orientation and medical attention. A problem solving approach in conjunction with the interest, emotional support, and empathic curiosity of the therapist can help patients who might not return or accept treatment approaches that deviate from their traditional or alternative approaches. If confronted with the contemporary seemingly impersonal and cold approaches, most treatment interventions will fail.

\section{Psychopharmacological Interventions}

The use of psychopharmacological agents amongst the poor in the treatment of depression is no different than in the more affluent populations. Decisions should be based on clear clinical grounds and drugs adjusted to patients' needs. With a good effort in developing therapeutic alliance, and actively involving patients in their own treatment and active effort to procure the drugs needed for the patients, patients who perceive a genuine effort by the clinician to help will generally comply with the full courses of treatment. It should be stressed that the physicians should be aware of transportation problems, difficulty in child and elderly care arrangements, conflict of working hours, family disapproval and the stigma of mental illness in plans for follow-up visits.

\section{SUMMARY}

Among affective disorders, depression is much more common and ubiquitous in its distribution. There is no clear consensus regarding its clinical manifestations. The symptoms vary widely and so does the cause of the illness. The clinical picture is influenced by the type of depressive illness, the personality of the patient and the 
socio-cultural milieu in which it occurs. Contrary to earlier observations, depression with its core features is a universal phenomena of human experience which can occur in association with many life events and in response to daily frustrations and disappointments. There is a need for a closer look at diagnostic criteria of depression among the poor, variations in clinical manifestations and treatment strategies.

Some variations in the clinical manifestations could be attributed to factors of varied definitions of terminology and concepts of depression and different skills and tools to detect such cases in the population. These are influenced by various ecological, cultural and social factors and influence both the incidence and clinical manifestation of depression. When this information is available, it is not only useful in better intervention and treatment of these populations, but in prevention as well.

This paper raises questions and thoughts about depression amongst the poor and the need for a more intense look at the psychosocial aspects of depression.

\section{REFERENCES}

1. Acostal FX, Yamemoto J, Evans LA: Effective psychotherapy for low income and minority patients. N.Y. Plenum, 1982

2. Ryan W: Blaming the victim, Rev. Ed., N.Y.

3. Lorion RP: Social Policy 8:17-27, 1977

4. Prince R: Psychotherapy and the chronically poor. In J.C. Finney (Ed) Culture change and mental health and poverty. Lexington: Univ of Kentucky Press, 1969

5. Schonfield W: Psychotherapy: The purchase of friendship. Englewood Cliffs, N.J., Prentice Hall, 1964

6. Halleck SL: The politics of therapy. NY Science House, 1971

7. Bart PB: Ideologies and utopias of psychotherapy. In P.M. Roman and H.M. Trice (eds). The sociology of psychotherapy. NY Jason Aronson, 1974

8. Montigo Jorge: Psychotherapy 22: (2) 436-440, 1985

9. Weiss M: Psychosocial and cross cultural issues in depression in affective disorders. Recent research and related developments. S.M. Channabasavanna and S.A. Shah (Ed). Proceedings of US-Indo Symposium, Nov 14-16 (1985). NIMH and Neuro Sciences. Bangalore 560029 India. 